\title{
Ps.-Platon
}

\section{Über den Tod}

\author{
Eingel., übers. u. mit interpretierenden Essays versehen v. Irmgard Männlein- \\ Robert, Oliver Schelske, Michael Erler u.a.
}

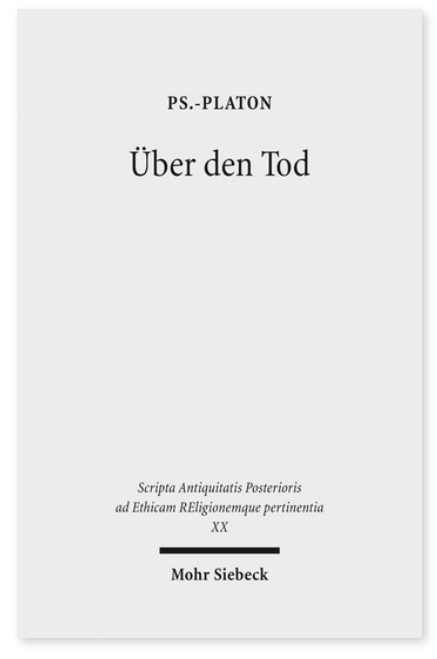

2012. XI, 224 Seiten. SAPERE XX

ISBN 978-3-16-156435-2

DOI 10.1628/978-3-16-156435-2 eBook PDF

ISBN 978-3-16-151904-8

fadengeheftete Broschur 29,00€
Der unter dem Namen Platons überlieferte, vermutlich aus dem späten 1. Jahrhundert v. Chr. stammende Dialog mit dem Titel 'Axiochos' beschäftigt sich mit der anthropologisch zeitlosen Frage, was mit dem Menschen nach seinem Tod geschieht: Der Philosoph Sokrates wird zum sterbenskranken Axiochos gerufen, der Todesangst hat. Sokrates soll ihm diese nehmen und bringt in das gemeinsame Gespräch zuerst vor allem epikureische Argumente ein. Axiochos ist nicht überzeugt. Erst als Sokrates Argumente Platons vorbringt, gelingt es Axiochos, die Todesfurcht endgültig zu überwinden und sich sogar auf den Tod zu freuen. In diesem Band wird der pseudo-platonische Dialog 'Axiochos' erstmals philologisch und philosophisch in den Kontext des im späten 1. Jahrhundert v. Chr. aufkommenden sogenannten 'Mittelplatonismus' eingebettet sowie die intensive Rezeption dieser 'ars moriendi' in der Frühen Neuzeit behandelt.

Ps.-Platon Keine aktuellen Daten verfügbar.

Michael Erler Geboren 1953; Studium der Klassischen Philologie und Philosophie; 1977 Promotion; 1985 Habilitation; 1989 92 Professor (C3) für Klassische Philologie (mit Schwerpunkt Latein) in Erlangen; seit 1992 Professor für Klassische Philologie (mit Schwerpunkt Griechisch) in Würzburg; seit 2019 Seniorprofessor und Mitglied (chair) des Direktoriums des SieboldCollegium Institute for Advanced Studies (SCIAS) der Universität Würzburg.

Reinhard Feldmeier Geboren 1952; Promotion und Habilitation in Tübingen; Pfarrer der bayerischen Landeskirche; $1992-95$ Professur in Koblenz; 1995-2002 Professur in Bayreuth; seit 2002 Professor für Neues Testament in Göttingen; Mitglied der Akademie der Wissenschaften zu Göttingen.

Sven Grosse Geboren 1962; Studium der Ev. Theologie und Philosophie in München und Tübingen; 1993 Promotion; 1999 Habilitation; seit 2008 Professor für Historische und Systematische Theologie an der Staatsunabhängigen Theologischen Hochschule Basel.

Achim Lohmar ist Professor für Philosophie an der Universität Duisburg Essen.

Irmgard Männlein-Robert Geboren 1970; Studium der Klassischen Philologie und der Germanistik; 2000 Promotion; 2005 Habilitation; seit 2006 ordentliche Professorin für Klassische Philologie (Gräzistik) an der Universität Tübingen. https://orcid.org/0000-0003-0250-5427

Heinz-Günther Nesselrath Geboren 1957; 1976-81 Studium der Klassischen Philologie und der Alten Geschichte an der Universität zu Köln; 1981 Promotion; 1987 Habilitation; 1992-2001 vollamtlicher Professor für Klass. Philologie an der Universität Bern; seit 2001 Universitätsprofessor für Klass. Philologie an der Georg-August-Universität Göttingen.

Uta Poplutz Geboren 1971; 2009-10 Vertretungsprofessur für Neues Testament an der Universität Mainz; seit 2010 Lehrstuhlinhaberin für Biblische Theologie mit dem Schwerpunkt Exegese und Theologie des Neuen Testaments an der Bergischen Universität Wuppertal. https://orcid.org/0000-0002-6136-8621

Oliver Schelske 2004 Master of Studies, University of Oxford; 2010 Promotion, Universität Tübingen; seit 2012 HabilitationsProjekt; seit 2015 Akademischer Rat, LMU München.

Jetzt bestellen:

https://mohrsiebeck.com/buch/ueber-den-tod-9783161564352?no cache=1

order@mohrsiebeck.com

Telefon: +49 (0)7071-923-17

Telefax: $+49(0) 7071-51104$ 